\title{
Stability Analysis of Partially Submerged Landslide with the Consideration of the Relationship between Porewater Pressure and Seepage Force
}

\author{
Yang Wang $\mathbb{D}^{1},{ }^{1}$ Le Yu, ${ }^{1}$ Tianci Yin, ${ }^{1}$ Lanbing Yu, ${ }^{1}$ and Zhitao Huo ${ }^{2}$ \\ ${ }^{1}$ Engineering Faculty, China University of Geosciences, Wuhan, Hubei 430074, China \\ ${ }^{2}$ China Institute of Geo-Environment Monitoring, Beijing 100081, China \\ Correspondence should be addressed to Yang Wang; wangyangcug@126.com
}

Received 25 October 2017; Accepted 11 March 2018; Published 12 April 2018

Academic Editor: Liangping Li

Copyright (C) 2018 Yang Wang et al. This is an open access article distributed under the Creative Commons Attribution License, which permits unrestricted use, distribution, and reproduction in any medium, provided the original work is properly cited.

For partially submerged landslides, hydrostatic and hydrodynamic pressures, related to water level fluctuation and rainfall, are usually expressed in the form of porewater pressure, seepage force, and buoyancy. There are some connections among them, but it is very easy to confuse one force with another. This paper presents a modified mathematical expression for stability analysis of partially submerged landslide and builds the relationship between porewater pressures and buoyancy acting on the underwater zone of partially submerged landslide and the relationship among porewater pressures, seepage force, and buoyancy acting on partially submerged zone. The porewater pressures acting on the underwater slice are calculated using hydrostatic forces, and the porewater pressures acting on the partially submerged slice are estimated by an approximation of equipotential lines and flow lines under the steady state seepage condition. The resultant of the porewater pressures acting on the underwater slice equals the buoyancy, and that acting on the partially submerged slice is equivalent to the vector sum of seepage force and the buoyancy. The result shows there are two equivalent approaches for considering the effect of water on landslide stability in the limit equilibrium method. One is based on total unit weight and porewater pressures, and the other is in terms of the buoyant weight and the seepage force. The study provides a modified model for simplifying the complex boundary porewater pressures in limit equilibrium analysis for the stability of the partially submerged landslide.

\section{Introduction}

Water, including groundwater and reservoir water, has long been considered as one of the most significant factors responsible for landslide failures, which is affected by water level fluctuation and rainfall in partially submerged landslides [15]. Statistics data from $\mathrm{He}$ et al. [6] showed that about $94 \%$ of landslides are triggered by rain and water storage in the TGR Region. The combined seepage-slope stability analyses in Mountain Toc of Italy by Paronuzzi et al. [7] demonstrated that the decreases in safety factors caused by filling and drawdown of the Vajont reservoir and heavy rainfall were about $12 \%$ and $3 \%$. The significant examples related to the water level fluctuation and rainfall have been recorded and discussed by researchers, such as rainfall-induced landslides of the Iva Valley in Southeastern Nigeria [8], landslides triggered by the July 2011 intense rainstorm in Korea, the June 2013 extreme rainfall in India and the October 2013 heavy rainfall associated with the typhoon in Japan [9-11], and landslide events associated with the water level fluctuation and rainfall [12-19].

Forces acting on landslide, related to water level fluctuation and rainfall, mainly include hydrostatic and hydrodynamic pressures. For partially submerged landslides, these forces are usually expressed in the form of porewater pressure, seepage force, and buoyancy. Some studies show that there are some connections between one force and another. The porewater pressure is considered as internal force and has the effect of reducing internal energy dissipation for a given collapse mechanism. However it may also be regarded as external forces, and its contribution can be included in the virtual work equations through the seepage force and buoyant 


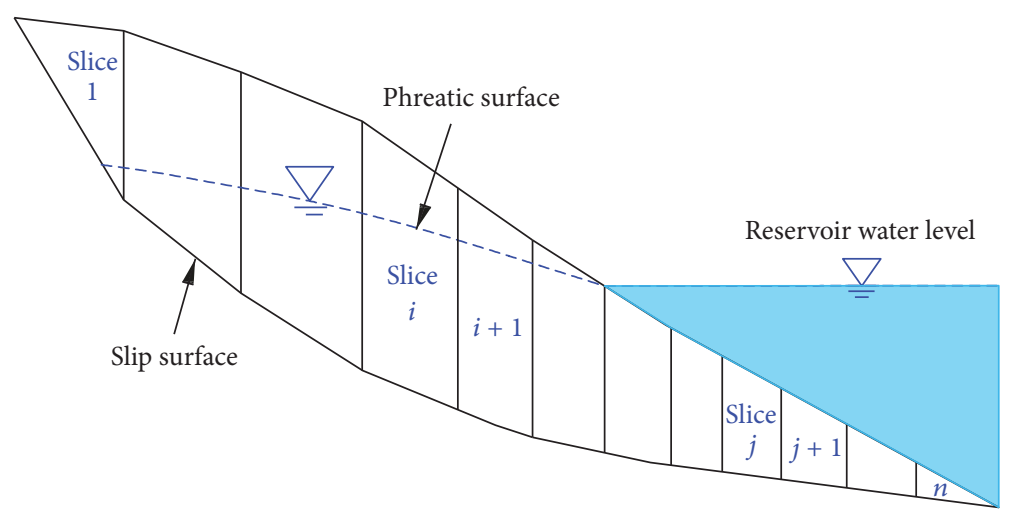

FIGURE 1: Division of a partially submerged landslide into vertical slices.

terms [20-22]. Water pressures on the face of a partially submerged landslide can be replaced by forces and moments which are directly added to slices or by a strengthless soil layer with self-weight equivalent to water weight or by an end force on slip surface at the toe of the landslide [23].

In some previous studies about the limit equilibrium methods of landslide stability, there are still some differences in analysing and using these forces related to hydrostatic and hydrodynamic pressures. Yamin and Liang [24] developed a limiting equilibrium method of slices for calculating global factor of safety of a slope and accounted for porewater pressure at the slice base related to its effective stress. However, they did not discuss the porewater pressure acting on the vertical boundaries of the slice. Li and Liang [25] only considered porewater pressure at the slice base when applying the limit equilibrium method to the interslice forces of a drilled shaft slope system. Zhou et al. [26] used the limiting equilibrium method to calculate the lateral force acting on the piles and considered the effect of the porewater pressure on the lateral forces of stabilizing piles in terms of the seepage force and the buoyant weight. Some used the porewater pressure on the base of the landslide [24, 25, 2729 ], some others allowed for boundary water pressures of slices [30], and others accounted for the seepage pressure $[26,31,32]$. Therefore, it is very easy to confuse one force with another.

This paper presents a modified expression for stability analysis of partially submerged landslide based on considering hydrostatic and hydrodynamic pressures acting on the underwater zone and partially submerged zone of the partially submerged landslides. Two relationships, including the relationship between porewater pressures and buoyancy acting on the underwater zone of partially submerged landslide and the relationship among porewater pressures, seepage force, and buoyancy acting on partially submerged zone, are clarified in detail. Two equivalent approaches are proposed to consider the effect of water on landslide stability in the limit equilibrium method of slices. One is based on the total unit weight and the porewater pressures, and the other is in terms of the buoyant weight and the seepage force. The latter is simpler to determine the safety factor of partially submerged landslide.

\section{Porewater Pressures of a Partially Submerged Landslide}

2.1. Porewater Pressures Acting on an Underwater Slice. A partially submerged landslide can be divided into the underwater zone and partially submerged zone. A typical cross section of a partially submerged landslide is shown in Figure 1. Two types of slices, underwater slice (Slice $j$ ) and partially submerged slice (Slice $i$ ), are bounded by the reservoir water surface.

When analysing forces acting on an underwater slice (Figure 2), we posit that reservoir water is under static condition, and the boundary porewater pressures can be calculated as

$$
\begin{aligned}
& P_{1}=0.5 r_{w}\left(h_{A}+h_{D}\right) l_{A D} \\
& P_{2}=0.5 r_{w}\left(h_{D}+h_{C}\right) l_{C D} \\
& P_{3}=0.5 r_{w}\left(h_{B}+h_{C}\right) l_{B C} \\
& P_{4}=0.5 r_{w}\left(h_{A}+h_{B}\right) l_{A B},
\end{aligned}
$$

where $P_{1}, P_{2}, P_{3}$, and $P_{4}$ are the porewater pressures acting on its four sides of slice $j, l_{A D}, l_{C D}, l_{B C}$, and $l_{A B}$ are the lengths of four sides, and $r_{w}$ is the unit weight of water.

\subsection{Porewater Pressures Acting on a Partially Submerged Slice.} When a phreatic surface of the partially submerged zone is defined, the porewater pressures are calculated for the steady state seepage condition by drawing a flow net (Figure 3 ). The actual pressure head at point $C$ can be obtained by drawing an equipotential line $(C D)$ through that point. But the actual seepage and porewater pressures are complex; it is necessary to use simple approximations [33-35]. One approximation is to define the porewater pressures using a line $M N$ that represents a phreatic surface $(A B)$ and to approximate the equipotential line as a straight line $C E$ which is perpendicular to the straight line $M N$ [33]. The porewater pressure can be represented as a function of the hydraulic head. Under the steady state seepage conditions, the hydraulic head of the line $C E$ can be described by

$$
h=\frac{u_{C}}{\gamma_{w}}+z_{C}=\frac{u_{E}}{\gamma_{w}}+z_{E},
$$



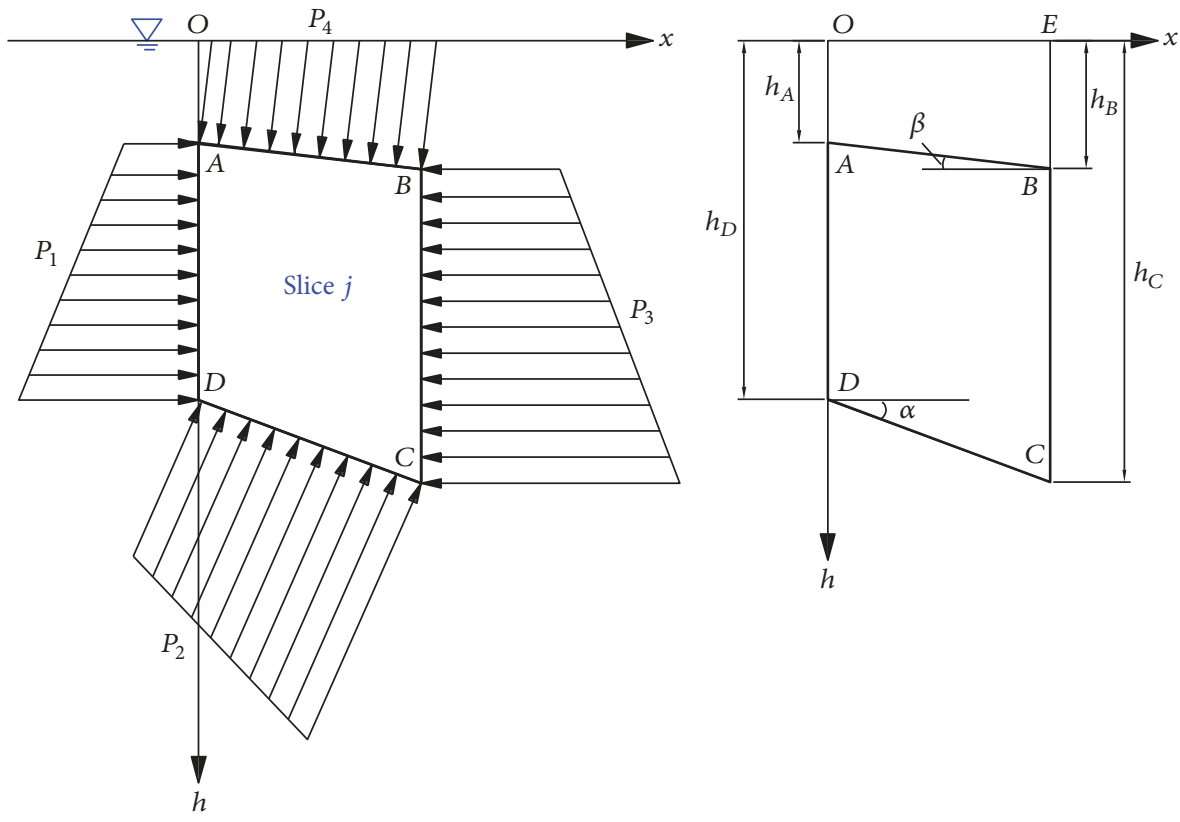

Figure 2: Porewater pressures acting on four sides of an underwater slice.

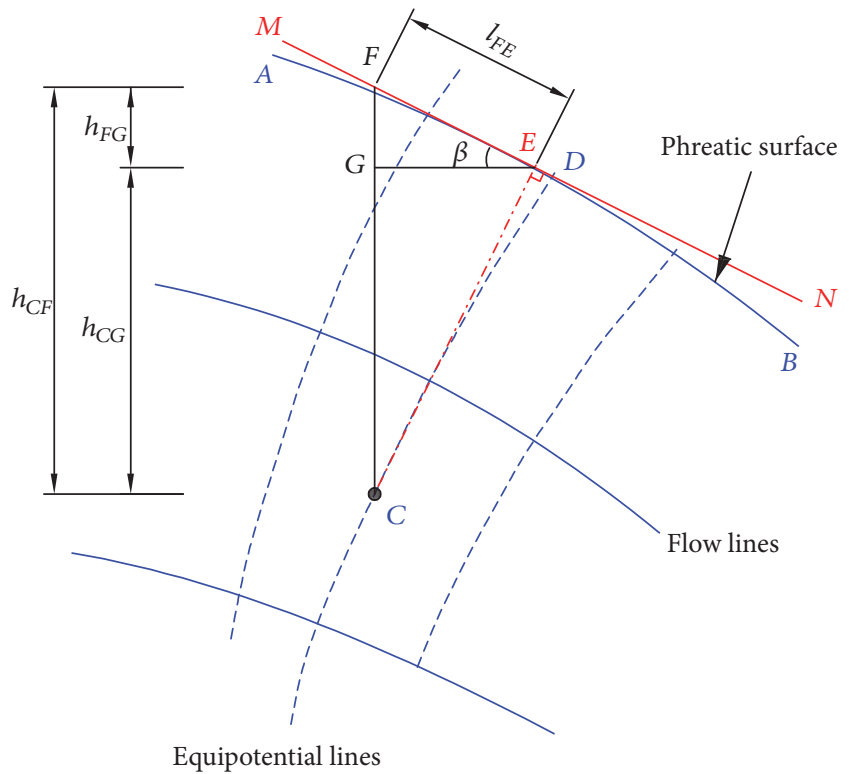

FIGURE 3: Approximation of the porewater pressure from flow net.

where $h$ is the hydraulic head, $u_{C}$ and $u_{E}$ are the porewater pressures of the point $C$ and point $E$, respectively, and $z_{C}$ and $z_{E}$ are the elevation heads of the point $C$ and point $E$, respectively.

The phreatic surface is considered to be a flow line and a line of the atmospheric pressure or zero pressure, and (2) can be written as

$$
u_{C}=\gamma_{w}\left(z_{E}-z_{C}\right)=h_{C F} \cos ^{2} \beta
$$

The hydraulic gradient of the seepage can be approximately estimated by examining the hydraulic head difference between point $F$ and point $E$ on the phreatic surface

$$
i_{E F}=\frac{h_{F G}}{l_{F E}}=\sin \beta .
$$

The porewater pressures acting on a partially submerged slice are shown in Figure 4. According to (3), these forces can be calculated as

$$
\begin{aligned}
& P_{1}=0.5 r_{w} l_{A D}^{2} \cos ^{2} \beta, \\
& P_{2}=0.5 r_{w}\left(l_{A D}+l_{B C}\right) l_{C D} \cos ^{2} \beta, \\
& P_{3}=0.5 r_{w} l_{B C}^{2} \cos ^{2} \beta .
\end{aligned}
$$

\section{Relationship between Porewater Pressures and Seepage Force}

3.1. Resultant of the Porewater Pressures Acting on the Underwater Slice. The porewater pressures, acting on four sides of the underwater slice (Figure 2), are resolved into two directions which are parallel and perpendicular to the slice base. The resultants of these forces acting on the slice can be derived as

$$
\begin{aligned}
N_{P} & =P_{2}+\left(P_{1}-P_{3}\right) \sin \alpha-P_{4} \cos (\alpha-\beta), \\
T_{P} & =\left(P_{1}-P_{3}\right) \cos \alpha+P_{4} \sin (\alpha-\beta),
\end{aligned}
$$

where $N_{P}$ is the resultant of the porewater pressures in direction perpendicular to the slice base, $T_{P}$ is the their resultant in direction parallel to the slice base, $\alpha$ is the inclination of the slice base of slice $j$, and $\beta$ is the inclination of top slide of slice $j$. 

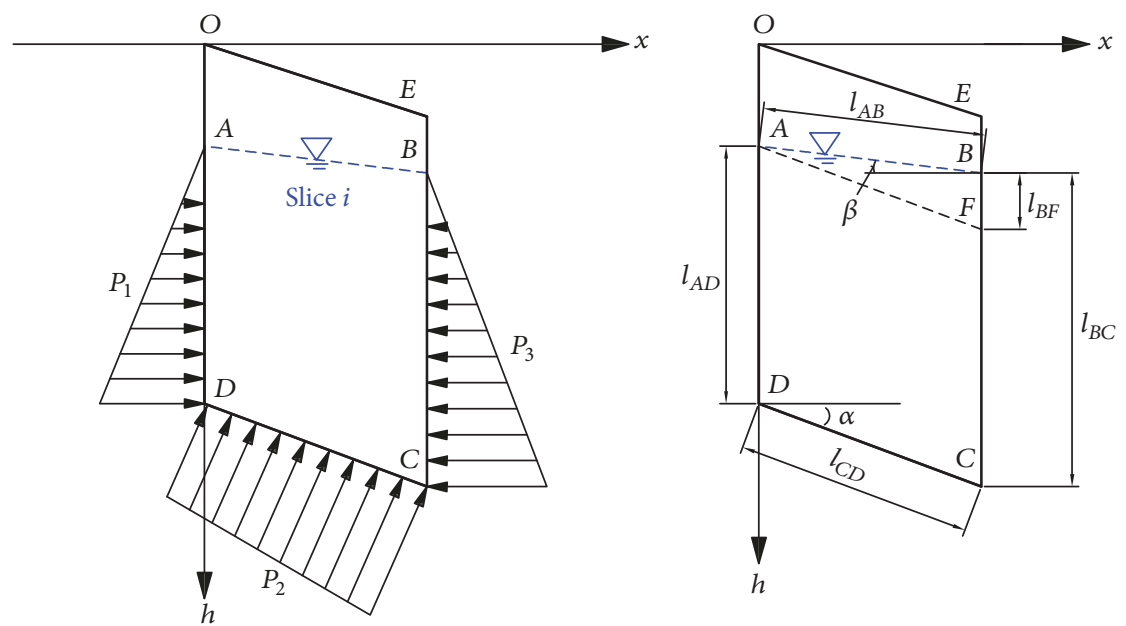

FIGURE 4: Porewater pressures acting on three sides of a partially submerged slice.

By substituting (1a), (1b), (1c), and (1d) into (6), we obtain

$$
\begin{aligned}
\frac{N_{P}}{0.5 r_{w}}= & \frac{h_{C}^{2}-h_{D}^{2}}{\sin \alpha}+\left(h_{D}^{2}-h_{A}^{2}-h_{C}^{2}+h_{B}^{2}\right) \sin \alpha \\
& -\frac{h_{B}^{2}-h_{A}^{2}}{\sin \beta}(\cos \alpha \cos \beta+\sin \alpha \sin \beta), \\
\frac{T_{P}}{0.5 r_{w}}= & \left(h_{D}^{2}-h_{A}^{2}-h_{C}^{2}+h_{B}^{2}\right) \cos \alpha \\
& +\frac{h_{B}^{2}-h_{A}^{2}}{\sin \beta}(\sin \alpha \cos \beta-\cos \alpha \sin \beta) .
\end{aligned}
$$

By rearranging the above two equations, the following expressions can be written as

$$
\begin{aligned}
& N_{P}=0.5 r_{w} \cos \alpha\left[\frac{h_{C}^{2}-h_{D}^{2}}{\tan \alpha}-\frac{h_{B}^{2}-h_{A}^{2}}{\tan \beta}\right]=r_{w} V \cos \alpha, \\
& T_{P}=0.5 r_{w} \sin \alpha\left[\frac{h_{D}^{2}-h_{C}^{2}}{\tan \alpha}+\frac{h_{B}^{2}-h_{A}^{2}}{\tan \beta}\right]=-r_{w} V \sin \alpha,
\end{aligned}
$$

where $V$ is the volume of slice $j$ in Figure 2.

3.2. Resultant of the Porewater Pressures Acting on the Partially Submerged Slice. All porewater pressures acting on the partially submerged slice, which are shown in Figure 4, are also decomposed into two directions which are parallel and perpendicular to the slice base, which can be expressed as

$$
\begin{aligned}
& N_{P}=P_{2}+\left(P_{1}-P_{3}\right) \sin \alpha, \\
& T_{P}=\left(P_{1}-P_{3}\right) \cos \alpha .
\end{aligned}
$$

By substituting (5a), (5b), and (5c) into (10), we obtain

$$
\begin{aligned}
N_{P} & =0.5 r_{w}\left[\left(l_{A D}+l_{B C}\right) l_{C D}-\left(l_{A D}+l_{B C}\right) l_{B F} \sin \alpha\right] \\
& \cdot \cos ^{2} \beta, \\
T_{P} & =-0.5 r_{w}\left(l_{A D}+l_{B C}\right) l_{B F} \cos \alpha \cos ^{2} \beta .
\end{aligned}
$$

Based on the Law of Sines, an equation relating the lengths of the sides of the triangle $A B F$ to the Sines of its angles can be given by

$$
\frac{l_{B F}}{\sin (\alpha-\beta)}=\frac{l_{A F}}{\sin \left(90^{\circ}+\beta\right)}=\frac{l_{C D}}{\cos \beta} .
$$

By substituting (12) into (11), the following expressions can be derived as

$$
\begin{aligned}
N_{P} & =0.5 r_{w}\left(l_{A D}+l_{B C}\right) \\
& \cdot l_{C D}\left[\cos ^{2} \beta-\sin (\alpha-\beta) \sin \alpha \cos \beta\right], \\
T_{P}= & -0.5 r_{w}\left(l_{A D}+l_{B C}\right) l_{C D} \sin (\alpha-\beta) \cos \alpha \cos \beta .
\end{aligned}
$$

Trigonometric functions using functional equations in terms of properties like the sum and difference formulas of two angles are applied to transformation of equations. The expressions above can be written as

$$
\begin{aligned}
N_{P} & =0.5 r_{w}\left(l_{A D}+l_{B C}\right) \\
& \cdot l_{C D}\left[\cos ^{2} \alpha+\sin (\alpha-\beta) \cos \alpha \sin \beta\right] \\
& =r_{w} V_{d}[\cos \alpha+\sin (\alpha-\beta) \sin \beta], \\
T_{P} & =0.5 r_{w}\left(l_{A D}+l_{B C}\right) \\
& \cdot l_{C D}[\cos \alpha \cos (\alpha-\beta) \sin \beta-\cos \alpha \sin \alpha] \\
& =r_{w} V_{d}[\cos (\alpha-\beta) \sin \beta-\sin \alpha],
\end{aligned}
$$

where $V_{d}$ is the volume of the section $A B C D$ below the phreatic surface of slice $i$ in Figure 4 .

3.3. Relationship between Porewater Pressures and Seepage Force. The seepage force is directly proportional to the hydraulic gradient and the soil volume below the phreatic surface $[26,31]$, which can be defined as

$$
P=r_{w} V_{d} i=r_{w} V_{d} \sin \beta .
$$




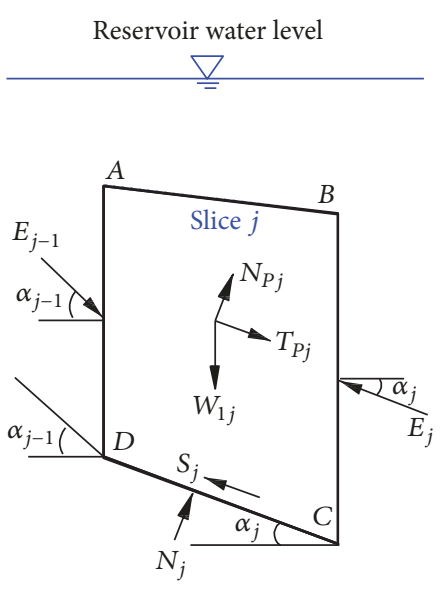

(a)

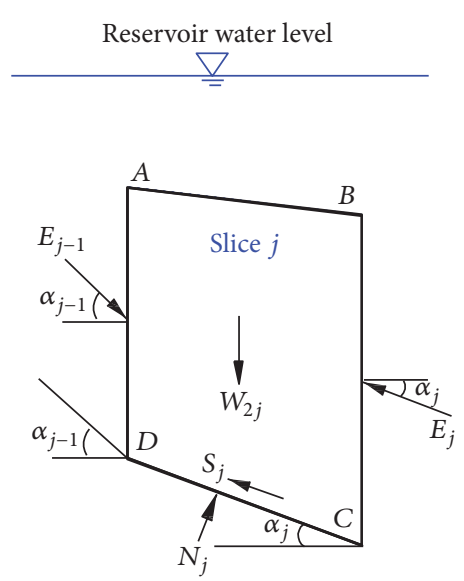

(b)

FIGURE 5: Forces acting on the underwater slice: (a) the porewater pressures based on (6) and (7); (b) substituting the buoyant weight for the porewater pressures and the total weight of the slice.

By substituting (15) into (14), the following expressions can be derived as

$$
\begin{gathered}
N_{P}=r_{w} V_{d} \cos \alpha+P \sin (\alpha-\beta), \\
T_{P}=P \cos (\alpha-\beta)-r_{w} V_{d} \sin \alpha .
\end{gathered}
$$

According to (8) and (9), the resultant of the porewater pressures acting on four sides of the underwater slice equals the buoyancy. Based on (16) and (17), the resultant of the porewater pressures acting on three sides acting on the partially submerged slice is equivalent to the vector sum of the buoyancy and the seepage force.

\section{Stability Analysis of Partially Submerged Landslide}

The following assumptions were applied to limit equilibrium method for the landslide stability $[25,26]$. (1) The landslide is divided into a series of vertical slices. (2) Each slice is assumed to be rigid. (3) The FOS is considered to be identical for all slices. (4) The thrust line of the interslice force on a lower slice is assumed to be parallel to the current slice base. (5) If the interslice force is negative, the value is assumed to be zero.

4.1. Limit Equilibrium Equations of the Underwater Slice. One approach, considering the effect of water on the underwater slices of partially submerged landslides in the limit equilibrium analysis, is based on porewater pressures. The resultant of the porewater pressures is based on (8) and (9). All forces are resolved into both the parallel and perpendicular directions to the slice base (Figure 5(a)), resulting in the following equations:

$$
\begin{array}{r}
W_{1 j} \cos \alpha_{j}-N_{P j}-N_{j}+E_{j-1} \sin \left(\alpha_{j-1}-\alpha_{j}\right)=0, \\
W_{1 j} \sin \alpha_{j}+T_{P j}+E_{j-1} \cos \left(\alpha_{j-1}-\alpha_{j}\right)-E_{j}-S_{j}=0 .
\end{array}
$$

The other approach directly uses the buoyancy. All forces are resolved into both directions (Figure 5(b)), and we obtain

$$
\begin{array}{r}
W_{2 j} \cos \alpha_{j}-N_{j}+E_{j-1} \sin \left(\alpha_{j-1}-\alpha_{j}\right)=0, \\
W_{2 j} \sin \alpha_{j}+E_{j-1} \cos \left(\alpha_{j-1}-\alpha_{j}\right)-E_{j}-S_{j}=0,
\end{array}
$$

where $W_{1 j}$ is the total weight of the slice $j$, which is calculated using saturated unit weight, $W_{2 j}$ is the buoyant weight of the slice, which is calculated using buoyant unit weight, $N_{j}$ is the normal force at the base of the slice, $E_{j-1}$ is the interslice force of slice $j-1$ acting on slice $j$ at the vertical boundary, $E_{j}$ is the interslice force of slice $j$ acting on slice $j+1$ at the vertical boundary, and $S_{j}$ is the mobilized shear strength along the base of the slice, which can be determined using the Mohr-Coulomb yield criterion:

$$
S_{j}=\frac{c_{j} \cdot l_{j}+N_{j} \tan \varphi_{j}}{\mathrm{Fs}},
$$

where $c$ is the cohesion of the slip surface, $l$ is the length of the slip surface, $\varphi$ is the friction angle of the slip surface, and Fs is the safety factor.

In fact, substituting (8) into (18), (20) can be obtained, and substituting (9) into (19), (21) can be obtained. Therefore, there are two equivalent approaches for considering the effect of water on the underwater zone of the partially submerged landslide in limit equilibrium analysis. One is based on porewater pressures, and the other uses the buoyant weight, without considering any porewater pressures.

4.2. Limit Equilibrium Equations of the Partially Submerged Slice. For the partially submerged slice, all forces, including the resultant of the porewater pressures in terms of (16) and (17), are also resolved into the same directions with the underwater slice as follows (Figure 6(a)): 


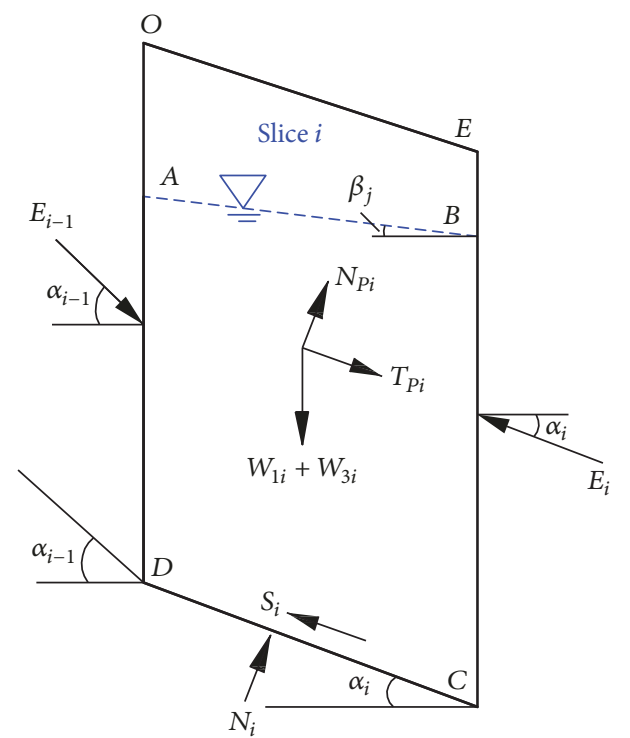

(a)

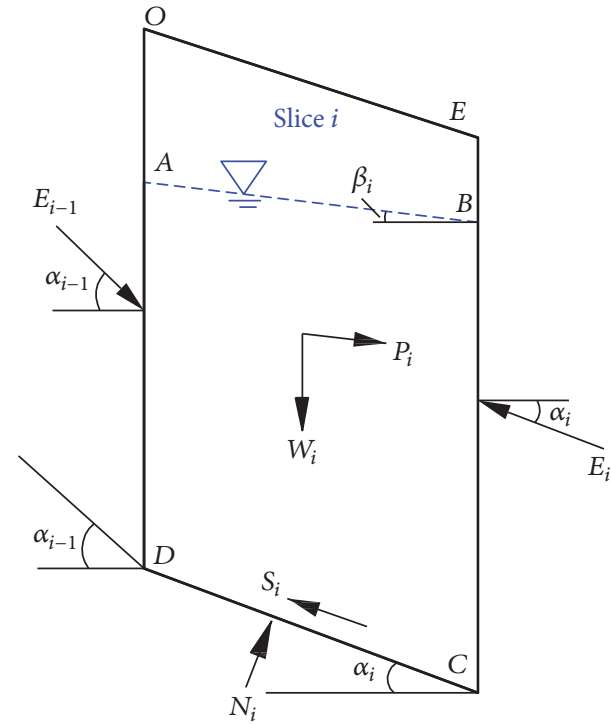

(b)

FIGURE 6: Forces acting on the partially submerged slice. (a) The porewater pressures based on (16) and (17); (b) substituting the seepage force and buoyant weight for the porewater pressures and the total weight of the slice.

$$
\begin{aligned}
& \left(W_{1 i}+W_{3 i}\right) \cos \alpha_{i}-N_{P i}-N_{i} \\
& \quad+E_{i-1} \sin \left(\alpha_{i-1}-\alpha_{i}\right)=0 \\
& \left(W_{1 i}+W_{3 i}\right) \sin \alpha_{i}+T_{P i}+E_{i-1} \cos \left(\alpha_{i-1}-\alpha_{i}\right)-E_{i} \\
& \quad-S_{i}=0
\end{aligned}
$$

The other approach directly uses the buoyancy and the seepage force. All forces are resolved into both directions (Figure 6(b)), and we obtain

$$
\begin{aligned}
& W_{i} \cos \alpha_{i}-P_{i} \sin \left(\alpha_{i}-\beta_{i}\right)-N_{i} \\
& \quad+E_{i-1} \sin \left(\alpha_{i-1}-\alpha_{i}\right)=0 \\
& W_{i} \sin \alpha_{i}+P_{i} \cos \left(\alpha_{i}-\beta_{i}\right)+E_{i-1} \cos \left(\alpha_{i-1}-\alpha_{i}\right)-E_{i} \\
& \quad-S_{i}=0
\end{aligned}
$$

where $W_{1 i}$ is the total weight of the section $A B C D$ below the surface phreatic, $W_{2 i}$ is the buoyant weight of the section $A B C D, W_{3 i}$ is the weight of the section $A B E O$ above the surface phreatic, and $W_{i}$ is the sum of $W_{2 i}$ and $W_{3 i}$.

If we substitute (16) into (23), (25) can be obtained, and substituting (17) into (24), (26) can be obtained. Therefore, there are also two equivalent approaches for considering the effect of water on the partially submerged zone. One is based on the porewater pressures and total weight, and the other uses the seepage force and buoyant weight, without considering any porewater pressures.

4.3. The Safety Factor of the Partially Submerged Landslide. It can be seen that both of (20) and (25) have the same forms, but (25) differs from (20) in two ways. One is that the weight term in (20) is the buoyant weight of the slice, while it is the sum of the weight of the section above the phreatic surface and buoyant weight of the section below the surface phreatic. The other is that there is the seepage force term in (25), not in (20). It is the same for (21) and (26). Thus, (25) and (26) are used not only for the partially submerged zone, but also for the underwater zone by regarding the seepage force as zero.

By adding the effect of the porewater pressure to the formula proposed by Yamin and Liang [24], we obtain a modified expression for calculating the safety factor of the partially submerged landslide stability using the seepage force and the buoyant weight terms, which is written as

$$
\mathrm{FS}=\frac{\sum_{i=1}^{n-1}\left(R_{i} \prod_{j=i}^{n-1} \psi_{j}\right)+R_{n}}{\sum_{i=1}^{n-1}\left(T_{i} \prod_{j=i}^{n-1} \psi_{j}\right)+T_{n}}
$$

with

$$
\begin{aligned}
R_{i} & =\left[W_{i} \cos \alpha_{i}-P_{i} \sin \left(\alpha_{i}-\beta_{i}\right)\right] \tan \varphi_{i}+c_{i} l_{i}, \\
T_{i} & =W_{i} \sin \alpha_{i}+P_{i} \cos \left(\alpha_{i}-\beta_{i}\right), \\
W_{i} & =V_{d i} \gamma^{\prime}+V_{u i} \gamma, \\
P_{i} & =\gamma_{w} V_{d i} \sin \beta_{i}, \\
\prod_{j=i}^{n-1} \psi_{j} & =\psi_{i} \cdot \psi_{i+1} \cdot \psi_{i+2} \cdots \psi_{n-1}, \\
\psi_{i-1} & =\cos \left(\alpha_{i-1}-\alpha_{i}\right)-\sin \cos \left(\alpha_{i-1}-\alpha_{i}\right) \frac{\tan \varphi_{i}}{\mathrm{Fs}},
\end{aligned}
$$

where $W_{i}$ is the weight of any slice $i, P_{i}$ is the seepage force, which is zero for an underwater slice, $V_{d i}$ is the volume of slice $i$ below the surface phreatic, $\gamma^{\prime}$ is buoyant unit weight of slice $i, V_{u i}$ is the volume of slice $i$ above the surface phreatic, 


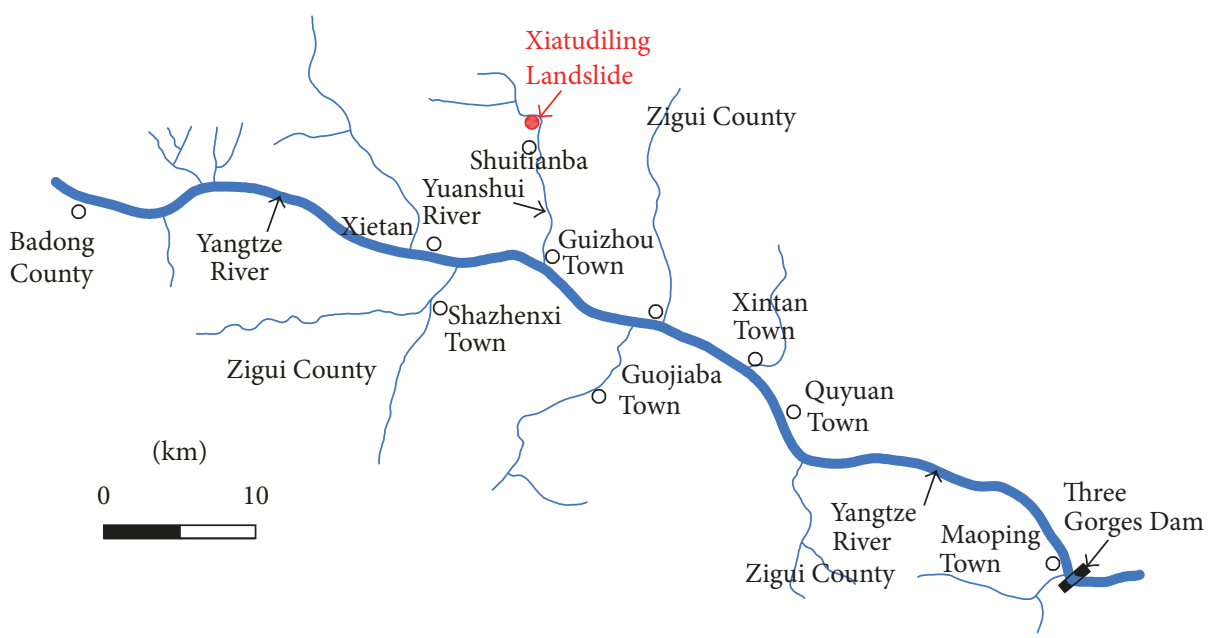

FIGURE 7: Location of the Xiatudiling landslide.

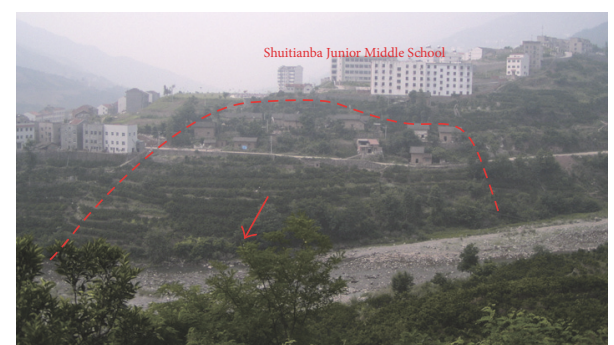

FIgURE 8: A panorama of the Xiatudiling landslide.

which is zero for an underwater slice, $r$ is the unit weight of slice $i$ above the surface phreatic, and $n$ is the slice number of a landslide.

\section{Case Study}

5.1. Characteristics of Xiatudiling Landslide. Xiatudiling landslide is located in Zigui County, Hubei Province, China (Figure 7). The elevations of the top and toe of the landslide are $205 \mathrm{~m}$ and $155 \mathrm{~m}$, respectively. The water level of the Three Gorges Reservoir fluctuates between $145 \mathrm{~m}$ and $175 \mathrm{~m}$; thus this landslide is a partially submerged slope. The landslide is about $170 \mathrm{~m}$ long and $14 \mathrm{~m}$ thick, with a volume of $25 \times 10^{4} \mathrm{~m}^{3}$. The width of the landslide is between $70 \mathrm{~m}$ and $150 \mathrm{~m}$ in the middle part and back part, with the biggest width of $210 \mathrm{~m}$ in the front part (Figures 8 and 9).

The Xiatudiling landslide is composed of loose rubble soil with a clay content of $15 \% \sim 40 \%$, the rubbles, which consist of sandstone and mudstone. Slip surface is mainly formed in the strongly weathered mudstone. Slip surface has a dip direction of $342^{\circ}$ and a dip angle of $8^{\circ}$. The exposed bedrock of the landslide is mainly red Jurassic Penglaizhen Formation $\left(J_{3} p\right)$, and the lithologies are mainly composed of purple mudstone, purple pelitic siltstone, and gray feldspar-quartz sandstone [36].

The Xiatudiling landslide is divided into 64 vertical slices (Figure 10). The cohesion of slip surface is $10 \mathrm{kN}$, and the
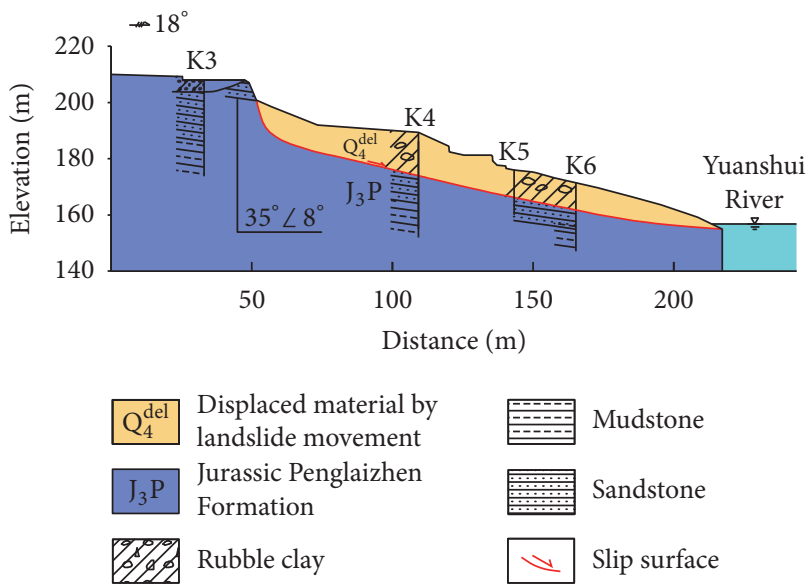

FIgURE 9: Longitudinal section of Xiatudiling landslide.

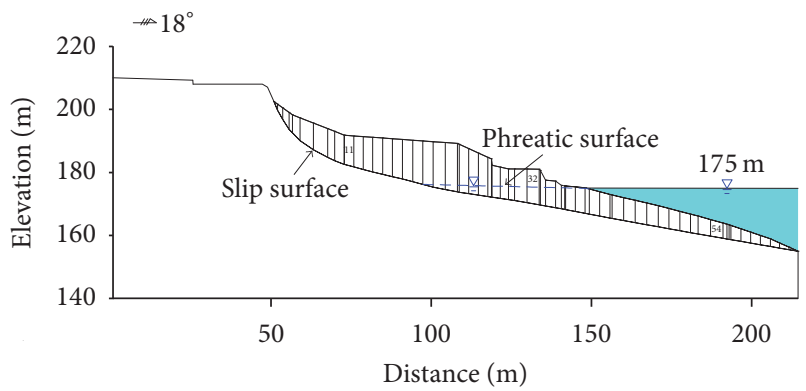

Figure 10: Division of the Xiatudiling landslide into slices.

friction angle is $11.8^{\circ}$. The dry unit weight of landslide material is $21.5 \mathrm{kN} / \mathrm{m}^{3}$, and the saturated unit weight is $23.5 \mathrm{kN} / \mathrm{m}^{3}$. The permeability coefficient of slide mass is $1.141 \mathrm{~m} / \mathrm{d}$, and the saturated water content of rubble soil is $26.20 \%$.

5.2. Results and Discussion. The safety factors of the $\mathrm{Xi}$ atudiling landslide are calculated by four models, Janbu, 
TABLE 1: The safety factors calculated by four models.

\begin{tabular}{lcccc}
\hline Model & Janbu & Morgenstern-Price & Spencer & This study \\
\hline Factor of safety & 1.110 & 1.097 & 1.100 & 1.130 \\
\hline
\end{tabular}

Morgenstern-Price, Spencer, and the method proposed by us. When the level of reservoir water is $175 \mathrm{~m}$, the safety factor calculated by the method proposed in this study, Janbu, Morgenstern-Price, and Spencer is 1.130, 1.110, 1.097, and 1.100 , respectively (Table 1 ). The safety factor proposed in this study is slightly larger than that by other models. The maximum difference is 0.033 and the rate of deviation is $2.92 \%$.

The difference is caused by the different assumption of interslice resultant force. Our method assumes the vector of interslice resultant force is parallel to slice base, while Janbu assumes the position of interslice horizontal force, Morgenstern-Price assumes a function relationship between interslice horizontal force and shear force, and Spencer assumes the dip of interslice resultant force is a constant.

\section{Conclusions}

The influences of water on the stability of the partially submerged landslide are usually expressed in the form of porewater pressure and seepage force in limit equilibrium analysis. This study builds the relationship between the porewater pressures and the seepage force by decomposition and composition of all boundary porewater pressures into two directions that are parallel and perpendicular to the slice base.

A partially submerged landslide is divided into many vertical slices that include underwater slices and partially submerged slices. A hydrostatic force approach is applied to calculate the boundary porewater pressure acting on an underwater slice, and a flow net approach is used to obtain the porewater pressures acting on a partially submerged slice. The resultant of the porewater pressures acting on the underwater slice equals the buoyancy, and that acting on the partially submerged slice is equivalent to the vector sum of the seepage force and the buoyancy.

There are two approaches for considering the effect of water on landslide stability in the limit equilibrium method of slices. One is based on total unit weight and porewater pressures acting, and the other is in terms of the buoyant weight and the seepage force. Both approaches are equivalent. The approach including the total unit weight and porewater pressures is complex. The porewater pressures of the underwater slice consist of four terms corresponding to the four sides, and those of the partially submerged slice are comprised of three terms corresponding to the three sides below the phreatic surface, while the other approach including the seepage force and buoyancy is simpler. Therefore, we choose the latter to consider the effect of water on the partially submerged landslide stability in limit equilibrium analysis, which offers a simple solution to complex boundary porewater pressures of slices in determining the factor of safety.
The proposed simplified method is used to calculate the safety factors of Xiatudiling landslide and is compared with that by Janbu, Morgenstern-Price, and Spencer model. The safety factor of this study is slightly larger than that by other models. The maximum difference is 0.033 and the rate of deviation is $2.92 \%$.

\section{Conflicts of Interest}

The authors declare that they have no conflicts of interest.

\section{Acknowledgments}

This research work was funded by the National Natural Science Foundation of China (no. 41572289, no. 41572292) and the follow-up work of geological disaster prevention projects in Three Gorges Reservoir (no. 000121 2015C C60 005).

\section{References}

[1] L. Cascini, S. Cuomo, M. Pastor, and G. Sorbino, "Modeling of rainfall-induced shallow landslides of the flow-type," Journal of Geotechnical and Geoenvironmental Engineering, vol. 136, no. 1, pp. 85-98, 2010.

[2] J. Du, K. Yin, and S. Lacasse, "Displacement prediction in colluvial landslides, Three Gorges Reservoir, China," Landslides , vol. 10, no. 2, pp. 203-218, 2013.

[3] D. Li, K. Yin, and C. Leo, "Analysis of Baishuihe landslide influenced by the effects of reservoir water and rainfall," Environmental Earth Sciences, vol. 60, no. 4, pp. 677-687, 2010.

[4] C. Liang, M. B. Jaksa, B. Ostendorf, and Y. L. Kuo, "Influence of river level fluctuations and climate on riverbank stability," Computers \& Geosciences, vol. 63, pp. 83-98, 2015.

[5] M. Zhang, Y. Yin, and B. Huang, "Mechanisms of rainfallinduced landslides in gently inclined red beds in the eastern Sichuan Basin, SW China," Landslides , vol. 12, no. 5, pp. 973983, 2015.

[6] K. He, X. Li, X. Yan, and G. Dong, "The landslides in the Three Gorges Reservoir Region, China and the effects of water storage and rain on their stability," Environmental Geology, vol. 55, no. 1, pp. 55-63, 2008.

[7] P. Paronuzzi, E. Rigo, and A. Bolla, "Influence of fillingdrawdown cycles of the Vajont reservoir on Mt. Toc slope stability," Geomorphology, vol. 191, pp. 75-93, 2013.

[8] O. Igwe, "The study of the factors controlling rainfall-induced landslides at a failure-prone catchment area in Enugu, Southeastern Nigeria using remote sensing data," Landslides, vol. 12, no. 5, pp. 1023-1033, 2015.

[9] T. R. Martha, P. Roy, K. B. Govindharaj, K. V. Kumar, P. G. Diwakar, and V. K. Dadhwal, "Landslides triggered by the June 2013 extreme rainfall event in parts of Uttarakhand state, India," Landslides, vol. 12, no. 1, pp. 135-146, 2015.

[10] S. Jeong, Y. Kim, J. K. Lee, and J. Kim, “The 27 July 2011 debris flows at Umyeonsan, Seoul, Korea," Landslides, vol. 12, no. 4, pp. 799-813, 2015.

[11] Y. Miyabuchi, F. Maeno, and S. Nakada, "The October 16, 2013 rainfall-induced landslides and associated lahars at Izu Oshima Volcano, Japan," Journal of Volcanology and Geothermal Research, vol. 302, pp. 242-256, 2015. 
[12] L. Müller, "The rock slide in the Vajont Valley," Rock Mechanics and Rock Engineering, vol. 2, pp. 148-212, 1964.

[13] F.-W. Wang, Y.-M. Zhang, Z.-T. Huo, T. Matsumoto, and B.-L. Huang, "The July 14, 2003 Qianjiangping landslide, three gorges reservoir, China," Landslides, vol. 1, no. 2, pp. 157-162, 2004.

[14] A. Panizzo, P. De Girolamo, M. Di Risio, A. Maistri, and A. Petaccia, "Great landslide events in Italian artificial reservoirs," Natural Hazards and Earth System Sciences, vol. 5, no. 5, pp. 733740, 2005.

[15] G.-Q. Chen, R.-Q. Huang, Q. Xu, T.-B. Li, and M.-L. Zhu, "Progressive modelling of the gravity-induced landslide using the local dynamic strength reduction method," Journal of Mountain Science, vol. 10, no. 4, pp. 532-540, 2013.

[16] X. Hu, M. Zhang, M. Sun, K. Huang, and Y. Song, "Deformation characteristics and failure mode of the Zhujiadian landslide in the three gorges Reservoir, China," Bulletin of Engineering Geology and the Environment, vol. 74, no. 1, pp. 1-12, 2015.

[17] G. Xu, W. Li, Z. Yu, X. Ma, and Z. Yu, "The 2 September 2014 Shanshucao landslide, Three Gorges Reservoir, China," Landslides, vol. 12, no. 6, pp. 1169-1178, 2015.

[18] Y. Yin, H. Wang, Y. Gao, and X. Li, "Real-time monitoring and early warning of landslides at relocated Wushan Town, the Three Gorges Reservoir, China," Landslides, vol. 7, no. 3, pp. 339-349, 2010.

[19] Y.-P. Yin, B. Huang, X. Chen, G. Liu, and S. Wang, "Numerical analysis on wave generated by the qianjiangping landslide in Three Gorges Reservoir, China," Landslides, vol. 12, no. 2, pp. 355-364, 2015.

[20] T. W. Miller and J. M. Hamilton, "New analysis procedure to explain a slope failure at the Martin Lake mine," Géotechnique, vol. 39, no. 1, pp. 107-123, 1989.

[21] R. L. Michalowski, "Slope stability analysis: A kinematical approach," Géotechnique, vol. 45, no. 2, pp. 283-293, 1995.

[22] J. Kim, R. Salgado, and H. S. Yu, "Limit analysis of soil slopes subjected to pore-water pressures," Journal of Geotechnical and Geoenvironmental Engineering, vol. 125, no. 1, pp. 49-58, 1999.

[23] E. N. Bromhead, A. J. Harris, and P. D. J. Watson, "Influence of pore water pressures in partly submerged slopes on the critical pool level," in Proceedings of the International Symposium on Slope Stability Engineering, N. Yagi, T. Yamagami, and J. C. Jiang, Eds., pp. 411-416, Matsuyama, Japan, 1999.

[24] M. Yamin and R. Y. Liang, "Limiting equilibrium method for slope/drilled shaft system," International Journal for Numerical and Analytical Methods in Geomechanics, vol. 34, no. 10, pp. 1063-1075, 2010.

[25] L. Li and R. Y. Liang, "Limit equilibrium based design approach for slope stabilization using multiple rows of drilled shafts," Computers \& Geosciences, vol. 59, pp. 67-74, 2014.

[26] C. Zhou, W. Shao, and C. J. van Westen, "Comparing two methods to estimate lateral force acting on stabilizing piles for a landslide in the three gorges reservoir, China," Engineering Geology, vol. 173, pp. 41-53, 2014.

[27] A. W. Bishop, "The use of the slip circle in the stability analysis of slopes," Géotechnique, vol. 5, pp. 7-17, 1955.

[28] N. R. Morgenstern and V. E. Price, "The analysis of the stability of general slip surfaces," Géotechnique, vol. 15, no. 1, pp. 79-93, 1965.

[29] A. G. Razdolsky, "Slope stability analysis based on the direct comparison of driving forces and resisting forces," International Journal for Numerical and Analytical Methods in Geomechanics, vol. 33, no. 8, pp. 1123-1134, 2009.
[30] Y. Zheng, W. Shi, and W. Kong, "Calculation of seepage forces and phreatic surface under drawdown conditions," Chinese Journal of Rock Mechanics and Engineering, vol. 23, pp. 32033210, 2004 (Chinese).

[31] B. D. Collins and D. Znidarcic, "Stability analyses of rainfall induced landslides," Journal of Geotechnical and Geoenvironmental Engineering, vol. 130, no. 4, pp. 362-372, 2004.

[32] H. Ghiassian and S. Ghareh, "Stability of sandy slopes under seepage conditions," Landslides, vol. 5, no. 4, pp. 397-406, 2008.

[33] J. Kim, R. Salgado, and J. Lee, "Stability analysis of complex soil slopes using limit analysis," Journal of Geotechnical and Geoenvironmental Engineering, vol. 128, no. 7, pp. 546-557, 2002.

[34] J. M. Duncan and S. G. Wright, Soil Strength and Slope Stability, John Wiley \& Sons, Inc., New York, NY, USA, 2005.

[35] L. Abramson, T. Lee, S. Sharma, and G. Boyce, Slope Stability and Stabilization Methods, John Wiley \& Sons, Inc., New York, NY, USA, 2nd edition, 2002.

[36] S. Yan, Y. Wang, H. Du, L. Yu, and S. Zheng, "Evaluation of the lateral forces acting on stabilizing piles considering the resistance of the lower zone of a landslide in the three Gorges Reservoir, China," Journal of Engineering Science and Technology Review, vol. 9, no. 6, pp. 170-177, 2016. 

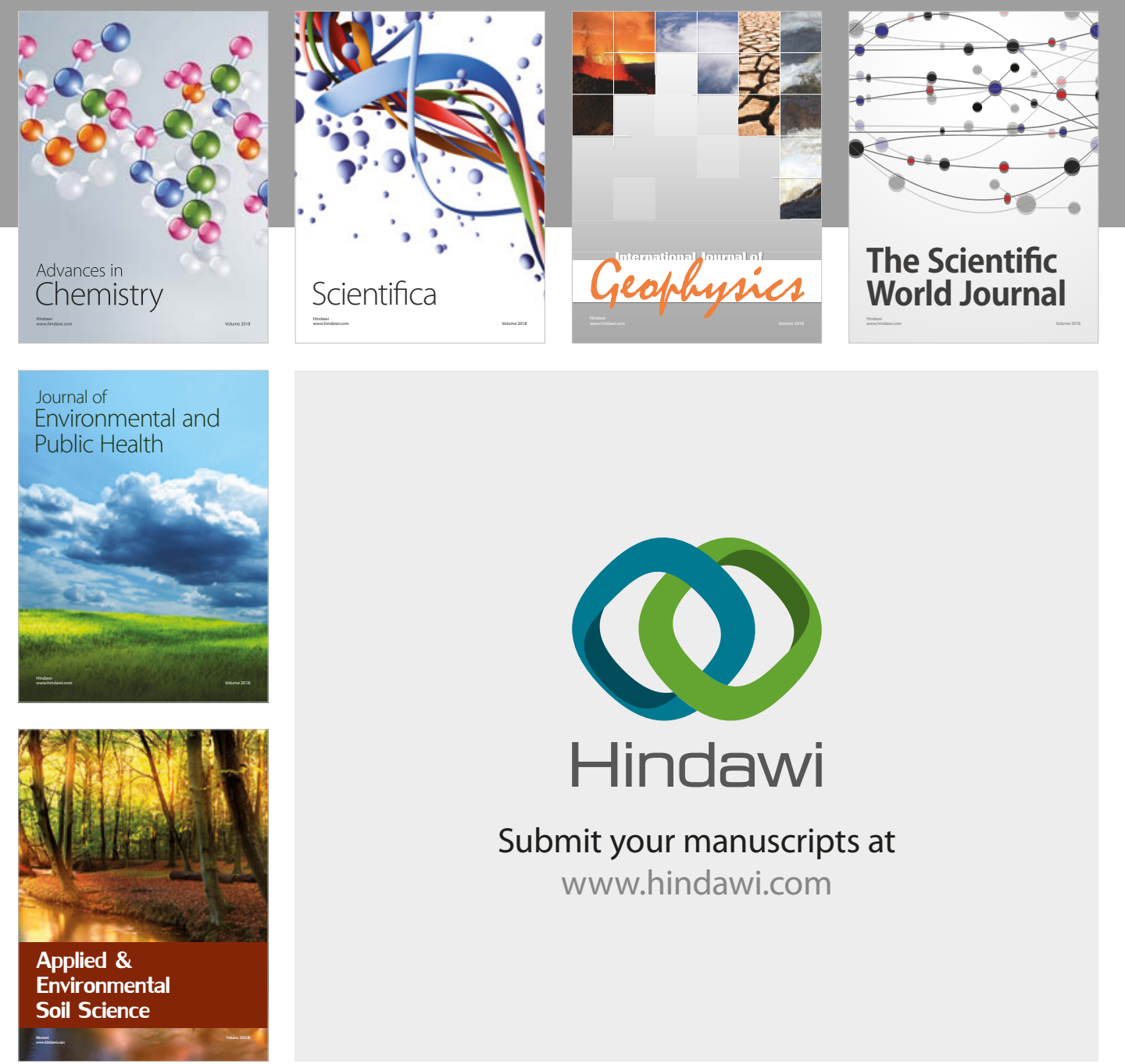

The Scientific

\section{World Journal}
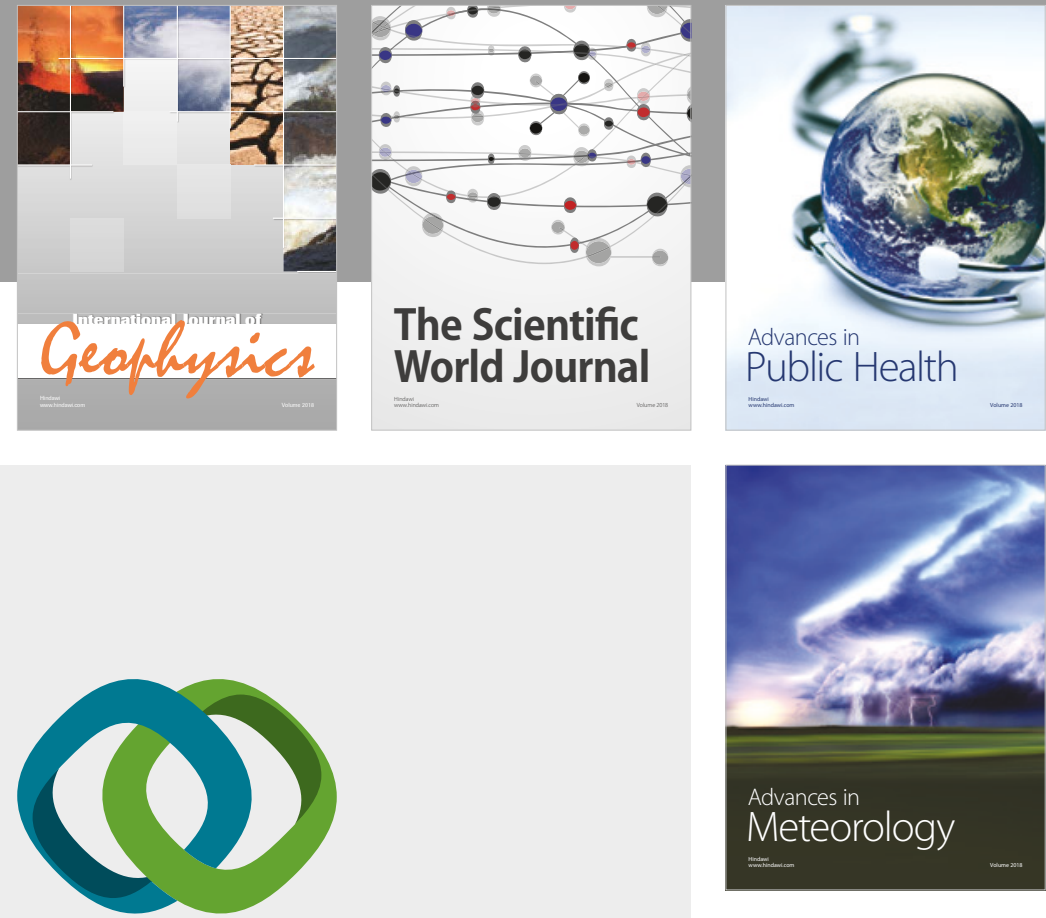

Advan

Public Health

\section{Hindawi}

Submit your manuscripts at

www.hindawi.com
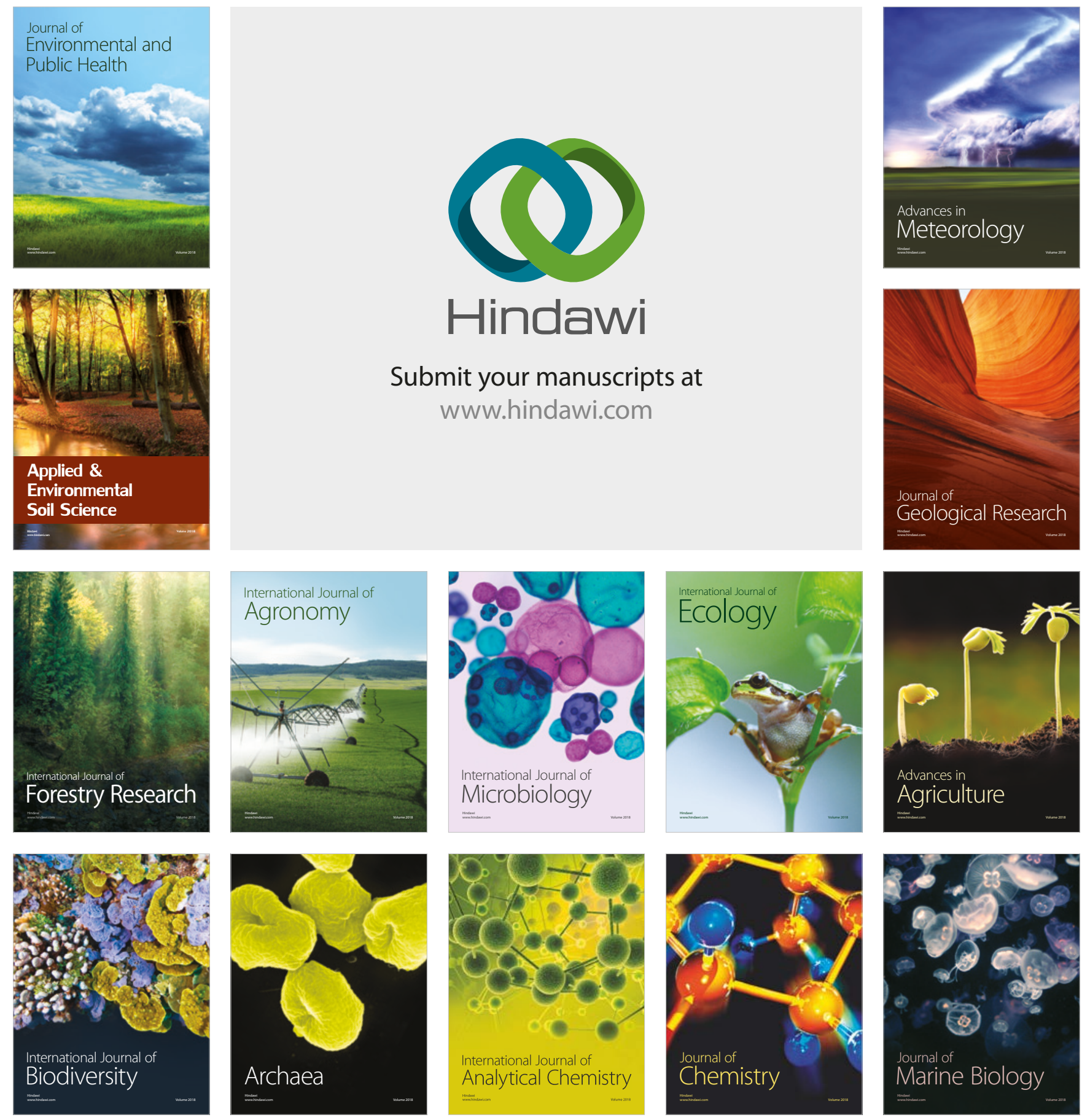